\title{
Comparing the spatio-temporal organization of joint spiking and local field potential oscillations in motor cortex
}

\author{
Michael Denker ${ }^{1 *}$, Lyuba Zehl' ${ }^{1}$ Thomas Brochier ${ }^{2}$, Alexa Riehle ${ }^{2,4}$, Sonja Grün 1,3,4 \\ From Twenty First Annual Computational Neuroscience Meeting: CNS*2012 \\ Decatur, GA, USA. 21-26 July 2012
}

Oscillations of the local field potential (LFP) are regarded as a signature of synchronized activity in neuronal networks. In primary motor (MI) and premotor (PM) cortex, LFPs typically exhibit such oscillatory activity in the beta range $(15-30 \mathrm{~Hz})$ during an instructed delay [1]. These oscillations tend to display a wave-like propagation across the cortical surface [2]. In parallel, temporally precise, behavior-related spike synchronization is often observed during periods of movement preparation and expectation [3]. In a previous study we demonstrated that the occurrence of significant spike coincidences is dependent on the phase of LFP beta oscillations [4]. In order to extend these studies to include positional information, we here study how the spatio-temporal organization of the LFP activity across cortical distances of several millimeters is related to that of spike synchronization [5].

Two monkeys were trained to press a switch with one hand, and then to grasp and pull an object using either a Side Grip or a Precision Grip. The force on the object could be either low or high. In order to allow the monkey to prepare the movement, the grip type was revealed at the beginning of an instructed delay of $1 \mathrm{~s}$ before the GO signal. In contrast, the force information was encoded by the GO signal itself. LFP and single unit activity was recorded simultaneously from a 100 electrode Utah array implanted at the MI/PMd border.

We analyze oscillatory activity in the beta band with respect to grip type and cortical position. Based on the phase synchrony of LFPs across electrodes, we quantify the spatial inhomogeneity of LFP propagation by its direction and speed in a time-resolved manner. In parallel, we

\footnotetext{
* Correspondence: m.denker@fz-juelich.de

'Institute of Neuroscience and Medicine (INM-6), Forschungszentrum Jülich, Germany

Full list of author information is available at the end of the article
}

compute spike correlations that significantly exceed chance level [5] as a function of temporal, spatial, and directional parameters. We find that the likelihood of synchronized spiking is behaviorally modulated in time, and decreases with distance between the two recorded neurons. Finally, we compare the spatial distribution of spike synchrony (represented as a graph of neurons exhibiting significant spike coincidences), and synchrony expressed by LFP oscillations in different epochs of the experimental paradigm.

\section{Acknowledgments}

Helmholtz Alliance on Systems Biology, European Union (FP7-ICT-2009-6, BrainScales), DAAD, Neuro_IC2010, CNRS-PEPS.

\section{Author details}

${ }^{1}$ Institute of Neuroscience and Medicine (INM-6), Forschungszentrum Jülich, Germany. ${ }^{2}$ Institut de Neurosciences de la Timone (INT), UMR 7289, CNRS Aix Marseille Univ., Marseille, France. ${ }^{3}$ Theoretical Systems Neurobiology, RWTH Aachen University, Germany. ${ }^{4}$ RIKEN Brain Science Institute, Wako-shi, Japan.

Published: 16 July 2012

\section{References}

1. Kilavik BE, Ponce-Alvarez A, Trachel R, Confais J, Takerkart S, Riehle A: Context-Related Frequency Modulations of Macaque Motor Cortical LFP Beta Oscillations. Cereb Cortex 2011, doi:10.1093/cercor/bhr299.

2. Rubino D, Robbins KA, Hatsopoulos NG: Propagating Waves Mediate Information Transfer in the Motor Cortex. Nat Neurosci 2006, 9:1549-1557.

3. Riehle A, Diesmann M, Grün S, Aertsen A: Spike Synchronization and Rate Modulation Differentially Involved in Motor Cortical Function. Science 1997, 278:1950-1953.

4. Denker M, Roux S, Lindén H, Diesmann M, Riehle A, Grün S: The Local Field Potential Reflects Surplus Spike Synchrony. Cereb Cortex 2011, 21:2681-2695.

5. Grün S, Diesmann M, Aertsen A: Unitary Events in Multiple Single-Neuron Spiking Activity: I. Detection and Significance. Neural Comp 2002, 14:43-80, Grün S, Diesmann M, Aertsen A: Unitary Events in Multiple SingleNeuron Spiking Activity: II. Nonstationary Data. Neural Comp 2002, 14:81-119. 
doi:10.1186/1471-2202-13-S1-P127

Cite this article as: Denker et al: Comparing the spatio-temporal organization of joint spiking and local field potential oscillations in motor cortex. BMC Neuroscience 2012 13(Suppl 1):P127.

Submit your next manuscript to BioMed Central and take full advantage of:

- Convenient online submission

- Thorough peer review

- No space constraints or color figure charges

- Immediate publication on acceptance

- Inclusion in PubMed, CAS, Scopus and Google Scholar

- Research which is freely available for redistribution

Submit your manuscript at 